\title{
Organizational Connections: The Moderation of Subordinate POS in the Relationship between LMX and Work Outcomes
}

\author{
Shingirayi M. Mushonga \\ Dept. of Management and Marketing \\ College of Business, Coppin State University \\ 2500 West North Ave., Baltimore MD 21216 \\ Tel: 410-951-6454Ｅmail: smushonga@coppin.edu
}

Received: Nov. 29, 2016 Accepted: Dec. 30, $2016 \quad$ Published: January 1, 2017

doi:10.5296/jmr.v9i1.10434 URL: http://dx.doi.org/10.5296/jmr.v9i1.10434

\begin{abstract}
Previous research on leader-member exchange (LMX) has often viewed the supervisor as the primary recipient of organizational resources. These resources often serve as incentives or catalysts for the subordinates to enter a dyadic relationship with the supervisor. However, this research has overlooked the salient role that subordinates play in the initiation of these relationships and their contributions to the organization. The aim of the present study was to examine LMX and perceived organizational support (POS) simultaneously from the subordinate's perspective and its impact in the development of LMX and work outcomes. Hayes' process macro (2013) was used to test the moderation model using a sample of 111 subordinates. Results confirm that subordinate POS moderates the relationship between (LMX) and various work outcomes (job satisfaction, organizational commitment, and organizational citizenship behavior (OCB)). Furthermore, the relationship between LMX and work outcomes was stronger when subordinates had high POS. The implications, limitations, and direction for future research are discussed.
\end{abstract}

Keywords: Social Exchange Theory, Leader-Member Exchange, Perceptions of Organizational Support, Job Satisfaction, Organizational Citizenship Behavior 


\section{Introduction}

The social exchanges that transpire within an organization have long been recognized as key factors in the achievement of the organization's goals. Researchers have invested an abundance of time and resources in an effort to understand how these exchange processes manifest within the organization. The social exchange theory (Blau, 1964) is based on the premise that "individuals willingly invest in relationships in which they provide services that benefit others but requiring an obligation by the other party to reciprocate by providing something in return" (Mushonga, Thiagarajan, \& Torrance, 2014, p.17). Therefore, individuals tend to exhibit increased levels of trust without any insight of the positive outcomes that may potentially result because these relationships are usually long-standing and reciprocal (Gouldner, 1960).

According to Settoon, Bennett, and Liden (1996), social exchanges can be conceptualized into two categories: global and dyadic exchanges. Global exchanges (commonly known as perceived organizational support (POS)) occur between an employee and the organization. As a central concept of the organizational support theory, POS encompasses the employees' belief of the organization's commitment to their general welfare, valued contributions, and provisions to organizational resources(Eisenberger, Huntington, Hutchison, \& Sowa, 1986; Erdogan \& Enders, 2007). Dyadic exchanges (commonly known as leader-member exchange (LMX)) encompass the interactions that occur between the subordinate and supervisor, more specifically, the quality of the exchange (Graen \& Schiemann, 1978).

Although well-documented similarities and distinctions exist between POS and LMX (Eisenberger, Shoss, Karagonlar, Gonzalez-Morales, Wickham, \& Buffardi, 2104; Roch \& Shanock, 2006; Settoon et al., 1996; Wayne, Shore, \& Liden, 1997), few studies have managed to integrate these two constructs (Wayne et al., 1997). For example, Erdogan and Enders (2007) integrated the two constructs by examining the moderation of supervisors' POS in the relationship between LMX, job satisfaction, and job performance. Their study clearly illustrated the salient role that supervisors play in connecting their exchanges with the organization to the exchanges with their subordinates. While their findings enhanced our understanding of the integration of POS and LMX from a supervisory perspective, they overlooked the importance of subordinates and their role in the exchanges with both the organization and supervisor. This is an integral concept because subordinates who experience high POS are likely to have access to valuable resources that may appeal to their supervisors. Consequently, supervisors may feel more inclined to develop high-quality relationships with these subordinates in an attempt to access those resources (Wayne et al., 1997). Subordinate POS and LMX have a symbiotic relationship in affecting work outcomes; however, there is a lack of research examining these constructs concurrently (Wayne et al., 1997).

Therefore, this study examines the moderating effects of subordinate POS in the relationship between LMX and work outcomes. By examining these two constructs simultaneously from a subordinate perspective, this study hopes to gain more insight as to how the relationship between the organization and subordinate (POS) affects the relationship between the subordinate and their supervisor's LMX quality which ultimately impacts subordinate work 
outcomes. Expectations are that different dynamics are in play when the subordinate has high POS as opposed to when the supervisor has high POS.

\section{Literature Review}

\subsection{Perceived Organizational Support (POS)}

Since POS references beliefs that are rooted in the employee's interpretation of the organization's actions, the employee's behavior reflects their perceptions of the organization. For example, when an organization is perceived to display a willingness to be empathetic to an employee's needs, the employee may feel more inclined to increase their productivity and display a higher sense of attachment to the organization. This empathetic gesture by the organization induces feelings of reciprocity on the part of the employee.

The norm of reciprocity (Gouldner, 1960) is vital in the POS process, especially when an employee experiences high POS. They may feel obligated to reciprocate the organization's support with positive work outcomes (i.e. job commitment, job performance, job satisfaction, organizational citizenship behavior (OCB)). According to Erdogan and Enders (2007), an employee may reciprocate by trickling down the effect of POS to other employees who lack such organizational support. Although research has predominately viewed subordinates as the primary recipients of this trickle-down effect, this study contends that the supervisor is just as likely to be a recipient as well. The omission of the supervisor as a recipient could be partly due to the fact that previous research viewed the supervisor as a pivotal role connecting subordinates to the organization. Despite the focus on supervisors as the intermediary between the subordinate and the organization, subordinates with high POS can directly access valuable resources from the organization and bypass their supervisors thus circumventing the chain of command. This notion is key because it challenges the status quo by clearly differentiating the supervisor as a separate entity from the organization.

\subsection{Leader-Member Exchange (LMX)}

Although LMX was first recognized almost four decades ago, it has evolved immensely over the years (Schriesheim, Castro, \& Cogliser, 1999). LMX is based on the two different levels of exchanges between a supervisor and his/her subordinates. On one hand, high-quality exchanges with subordinates in the "in-group" are characterized with trust, mutual respect, predilection, and resource sharing (Erdogan, Liden, \& Kraimer, 2006; Graen \& Uhl-Bien, 1995). While on the other hand, low-quality exchanges with subordinates in the "out-group" are characterized with quid pro quo transactions (Sparrowe \& Liden, 1997) and strictly contractual terms (Graen \& Uhl-Bien, 1995). One of the main premises of LMX has been the centrality of the supervisor in the development of LMX and the quality of exchange (Erdogan et al., 2006; Walumbwa, Mayer, Wang, Wang, Workman, \& Christensen, 2011). However, recent research on LMX has begun to look at the subordinate as an equal counter part to the supervisor in the LMX development process (Dulebohn, Bommer, Liden, Brouer, \& Ferris, 2012). Although the supervisor has been viewed as the prominent initiator of the development and quality of LMX, it is conceivable that subordinates with strong organization connections and access to valuable resources within the organization can potentially have the same impact. 
This paradigm shift of the subordinate's role in the development and quality of LMX is profound because it challenges the organization's status quo in traditional LMX research. The development and quality of LMX is dependent on the dual evaluations that occur between the supervisor and subordinate regarding their respective contributions (Graen \& Scandura, 1987). Oftentimes, the supervisor evaluates the subordinate's attractiveness based on their physical traits (Fiske, 1993) and skill and competence (Graen \& Linden, 1980). However, this supervisor centric perspective neglects the organizational connections and resources established by the subordinate.

\section{Hypotheses Development}

\subsection{LMX, POS, \& Job Satisfaction}

The positive relationship between LMX and job satisfaction has been well-established by previous research. The premise behind this positive relationship is based on subordinates who experience high quality exchanges. These subordinates, who are typically in the 'in-group', tend to have a relationship with their supervisor that is characterized by mutual trust and respect. Therefore, these subordinates are more likely to experience high levels of job satisfaction compared to subordinates in the 'out-group'. This link between LMX and job satisfaction tends to be leader-centric in assuming that the leader is the dominant party in the development of a LMX relationship. However, the flaw with this line of research is that it overlooks the subordinates in LMX development, especially subordinates with high POS.

When subordinates have high POS, they may have access to valuable resources that supervisors may want, prompting supervisors to recruit the high POS subordinates into their 'in-group'. This seems to suggest that supervisors will exert extra effort in engaging subordinates with high POS by promising to provide them a high LMX. Therefore, supervisors may enhance their chances of accessing the resources possessed by these subordinates. Subordinates who experience both high POS and LMX with the supervisors are more likely to experience even higher levels of job satisfaction than subordinates who experience low POS and LMX. When high POS and LMX subordinates know that they have support and access to resources needed to effectively perform job duties, they are more likely to be satisfied with their jobs.

Hypothesis 1: Subordinate POS will moderate the relationship between LMX and job satisfaction such that a stronger relationship will result when subordinate POS is high.

\subsection{LMX, POS, \& Organizational Commitment}

Previous research has found a positive relationship between LMX and organizational commitment (Liden, Wayne, \& Sparrowe, 2000; Schriesheim, Neider, Scandura, \& Tepper, 1992; Wayne, Coyle-Shapiro, Eisenberger, Liden, Rousseau, \& Shore, 2009). Becker (1992) posited that an individual's commitment is not only directed towards the organization, but also towards different entities (e.g. supervisors, coworkers, etc.) within the organization. Similarly, Stevens, Beyer, and Trice (1978) noted that commitment was composed of exchange-based and psychological-based approaches. Exchange-based approaches were based on the employee's evaluation of the extrinsic benefits that would have been forfeited if he/she left the 
organization, while psychological-based approaches viewed commitment as an employee's positive orientation towards helping the organization achieve its goal while maintaining membership.

The link between POS and organizational commitment has been well established throughout organizational support theory literature (Eisenberger et al., 1986). In fact, the authors found that POS increases an individual's commitment to the organization. Intuitively, this makes sense given that through the social exchange theory, subordinates with high POS are likely to have access to valuable resources needed to perform their duties or in some cases, use as leverage in other exchanges with other entities within the organization (e.g. supervisors and coworkers). As a result, these high POS subordinates might reciprocate the favorable arrangement by staying committed to the organization. After all, these subordinates are not guaranteed the same arrangement if they leave the organization. The subordinate's commitment is even stronger when a subordinate has high POS and high LMX.

Hypothesis 2: Subordinate POS will moderate the relationship between LMX and organizational commitment such that a stronger relationship will result when subordinate POS is high.

\subsection{LMX, POS, \& Organizational Citizenship Behavior (OCB)}

OCB encompasses the discretionary behaviors that exceed an employee's job expectations (Organ \& Near, 1985). These behaviors are not formally recognized by the organization nor are they rewarded (Williams \& Anderson, 1991). Previous research has explicitly demonstrated a positive relationship between LMX and OCB (Wang,Law, Hackett, Wang, \& Chen, 2005) which is predicated on the notion that subordinates engage in OCB as a function of their willingness to reciprocate the high quality relationship. For example, subordinates are more likely to go above and beyond their prescribed job duties when they perceive supervisors expressing compassion, utilizing diplomacy, and exhibiting willingness to share information with them.

Moorman, Blakely, \& Niehoff (1998) found a positive relationship between POS and OCB. The assumption is that high POS elicits OCB as employees make every effort to reciprocate the support they receive from the organization. When employees have high POS and quality exchanges with their supervisors, they are more likely to exhibit OCB, benefitting both the supervisor and organization as a way to reciprocate the favorable treatment. For example, Masterson, Lewis, Goldman, \& Taylor's (2000) study found that POS was a better predictor of organizational focused OCB and that LMX was a better predictor of supervisor focused OCB. Despite the authors' findings, this study utilized a more composite measure of OCB due to the reciprocal nature of POS and LMX (Wayne, Shore, Bommer, \& Tetrick, 2002).

Hypothesis 3: Subordinate's POS will moderate the relationship between LMX and OCB such that a stronger relationship will result when subordinate POS is high. 


\section{Method}

\subsection{Participants}

Data was collected from 111 employees working at an engineering firm located in the Southeastern region of the United States. The employee sample was $60 \%$ male with an average age of 33 years (ranging in age from 21-57 years). The majority of the participants $(85 \%)$ possessed a bachelor's degree and had worked for the organization an average of 4.3 yearswith2.1 years beingunder their current supervisor. The surveys were completed on-site and participants were guaranteed anonymity and could withdraw at any time.

\subsection{Measures}

The instruments utilized in this study to measure the constructs were obtained from previous research. The instruments were tested for reliability and validity in previous studies and were shown to meet the prescribed reliability and validity criteria. All responses were measured using a 7-point Likert scale ranging from 1 (strongly disagree) to 7 (strongly agree).

Leader-member exchange (LMX). LMX was measured using an8-item scale $(\alpha=.94)$ that was adapted by Bauer \& Green (1996) from by Scandura \& Graen's (1984) original 7-item scale. A sample item from the LMX scale includes "I usually know where I stand with my supervisor."

Perceptions of organizational support (POS). POS was measured using a 9-item shortened scale (Eisenberger et al., 1986). $(\alpha=.92)$. A sample item includes "In my organization, I am allowed to participate in decisions regarding my workload and performance standards."

Job satisfaction. Job satisfaction was measured using a 3-item scale that was adapted by Illies, Wilson, and Wagner (2009) from Brayfield and Rothe's (1951) original 5-item scale that assessed daily satisfaction. In addition, this study also utilized a 3-item scale $(\alpha=.83)$ of Job Satisfaction that was adapted by Yang, Mossholder \& Peng (2009) from Hackman and Oldham's (1975) measure of global satisfaction. A sample item from the daily satisfaction assessment includes "Right now I find real enjoyment in my work." A sample item from the global satisfaction assessment includes "All things considered, I am satisfied with my job."

Organizational commitment. Organizational commitment was measured using an 8-item scale $(\alpha=.83)$ that was developed byAllen and Meyer (1990) to assess affective commitment. A sample item includes "In my organization, I am allowed to participate in decisions regarding my workload and performance standards."

Organizational Citizenship Behavior (OCB). OCB was measured using a 7-item scale ( $\alpha$ $=.89$ ) adapted from Williams \& Anderson's (1991) OCB scale. A sample item includes "I help others who have a heavy load."

\section{Results}

Prior to testing the hypotheses, a correlation analysis was conducted in order to inspect the data for possible multicollinearity. The results of the correlation analysis are shown in Table 1, 


\section{Macrothink}

Journal of Management Research

ISSN 1941-899X 2017, Vol. 9, No. 1

which also displays the means, standard of deviation, and correlations among the variables in the study.

Table 1. Means, Standard Deviations, and Correlations

\begin{tabular}{|c|c|c|c|c|c|c|c|}
\hline Variable & Means & s. d. & 1 & 2 & 3 & 4 & 5 \\
\hline 1. LMX & 5.35 & 1.32 & & & & & \\
\hline 2. POS & 4.45 & 1.27 & $.502 * *$ & & & & \\
\hline 3. JBS & 5.27 & 1.11 & $.467 * *$ & $.451 * *$ & & & \\
\hline 4. OGC & 4.48 & 0.99 & $.414 * *$ & $.645 * *$ & $.610 * *$ & & \\
\hline 5. OCB & 5.46 & 0.91 & $.391 * *$ & $.314^{* *}$ & $.418^{* *}$ & $.487 * *$ & \\
\hline
\end{tabular}

Note: $\mathrm{LMX}=$ Leader Member-Exchange; POS = Perception of Organizational Support; JBS = Job Satisfaction; OGC $=$ Organizational Commitment; $\mathrm{OCB}=$ Organizational Citizenship Behavior $n=111 \quad * * p<.01$

Hypotheses were tested using Hayes' (2013) process macro to examine the moderating effect of POS in the relationship between LMX and work outcomes. The Hayes process macro estimates regression coefficients from 1000 bootstrap samples that are assumed to lack normal distribution. All three hypotheses were tested using model 1 of the process macro. Table 2 presents the results of the moderating effects of POS in the relationship between LMX and job satisfaction. The results clearly show a significant interaction between LMX and POS $(B=0.38$, $\mathrm{SE}=0.09, \mathrm{t}=-2.06, \mathrm{p}=0.04)$. Therefore, the results illustrate the moderating effects of POS in the relationship between LMX and job satisfaction, thus supporting hypothesis 1 . 
Table 2. Hypothesis 1 Outcomes from the Hayes process macro

\begin{tabular}{cccc}
\hline & \multicolumn{3}{c}{ Dependent variable (Job satisfaction) } \\
\cline { 2 - 4 } & $B$ & SE & t \\
\hline Constant & 5.49 & 0.08 & 67.91 \\
LMX & 0.41 & 0.15 & 2.68 \\
POS & 0.13 & 0.07 & 1.95 \\
Interaction & -0.38 & 0.09 & -2.06 \\
R2 & 0.26 & & \\
\hline
\end{tabular}

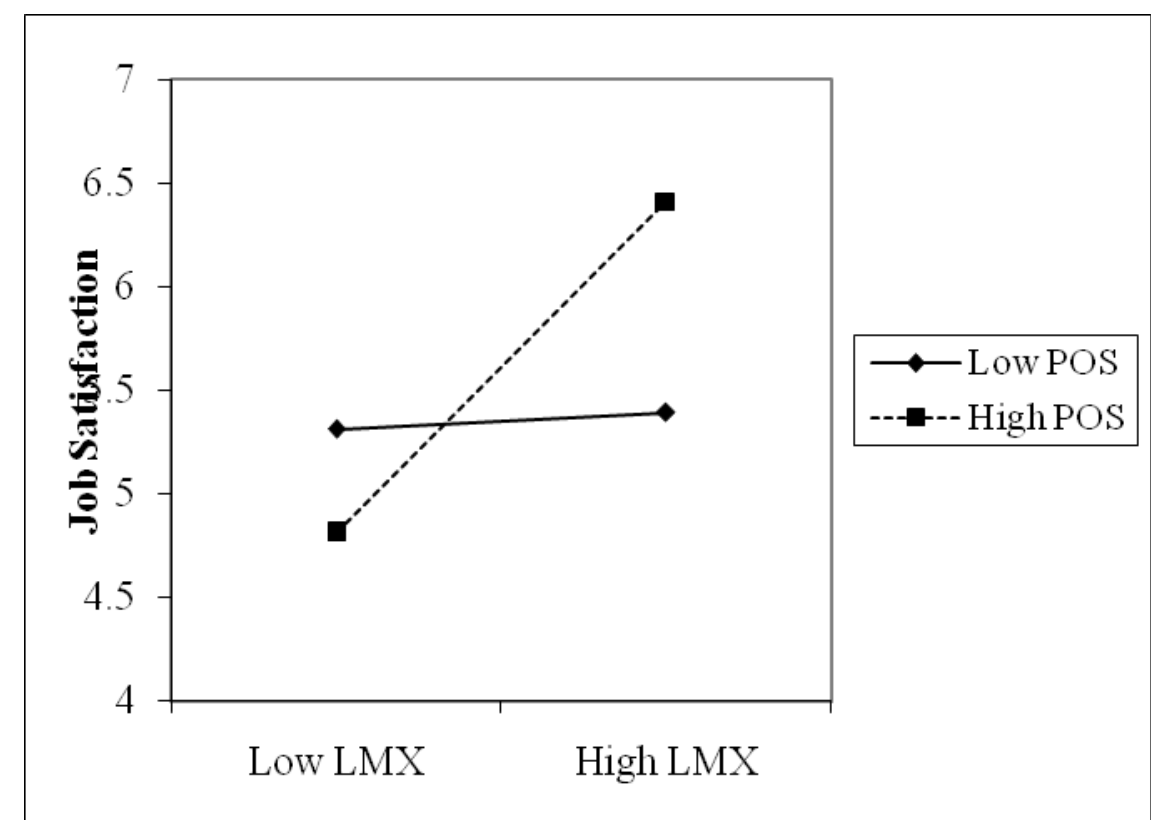

Figure 1. Subordinate POS as a moderator of LMX and job satisfaction.

Table 3 presents the results of the moderating effects of POS in the relationship between LMX and organizational commitment. The results clearly show a significant interaction between LMX and POS $(B=0.08, \mathrm{SE}=0.03, \mathrm{t}=-2.26, \mathrm{p}=0.02)$. Therefore, the results illustrate the moderating effects of POS in the relationship between LMX and organizational commitment and supports hypothesis 2 . 
Table 3. Hypothesis 2 Outcomes from the Hayes process macro

\begin{tabular}{llll}
\hline & \multicolumn{3}{l}{ Dependent variable (Organizational commitment) } \\
\cline { 2 - 4 } & $B$ & SE & T \\
\hline Constant & 5.48 & 0.96 & 56.9 \\
LMX & 0.42 & 0.12 & 1.78 \\
POS & 0.13 & 0.14 & 3.36 \\
Interaction & -0.08 & 0.03 & -2.26 \\
R2 & 0.69 & & \\
\hline
\end{tabular}

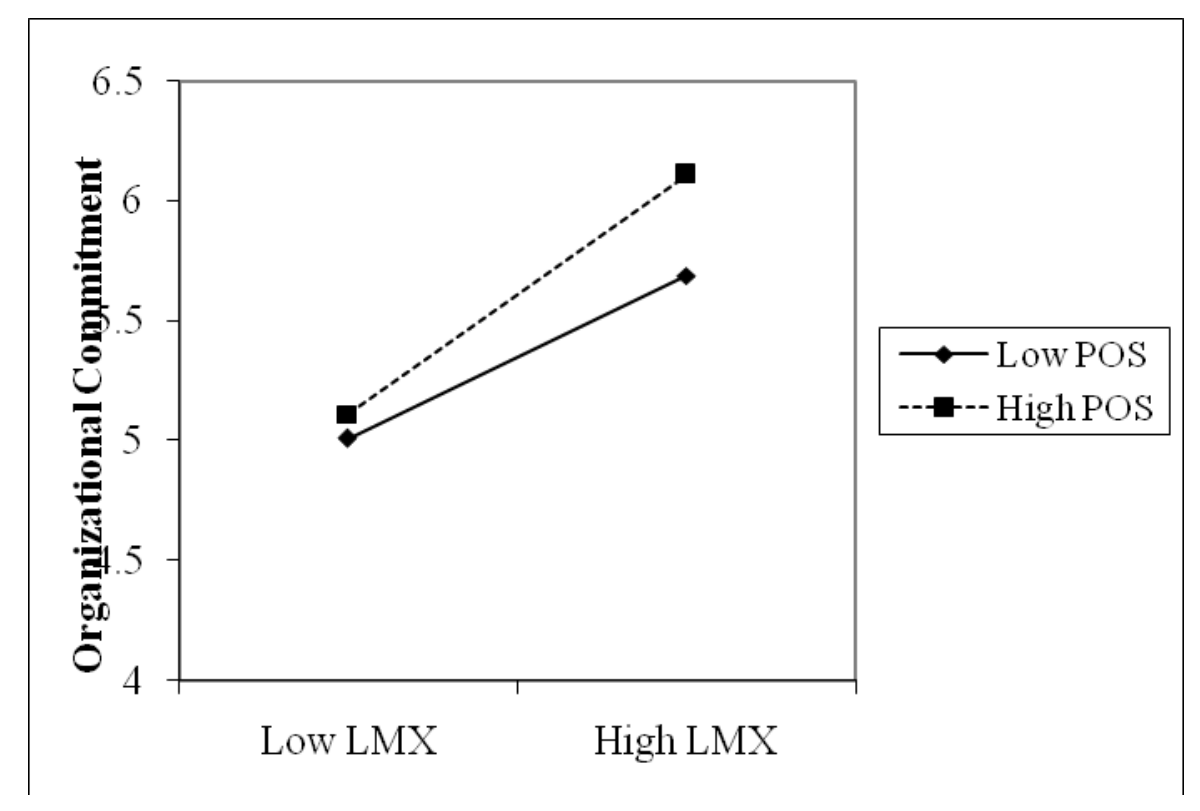

Figure 2. Subordinate POS as a moderator of LMX and organizational commitment.

Table 4 presents the results of the moderating effects of POS in the relationship between LMX and OCB. The results clearly show a significant interaction between LMX and POS $(B=0.13$, $\mathrm{SE}=0.05, \mathrm{t}=-2.74, \mathrm{p}=0$ ). Therefore, the results illustrate the moderating effects of POS in the relationship between LMX and OCBthus supporting hypothesis 3 . 
Table 4. Hypothesis 3 Outcomes from the Hayes process macro

\begin{tabular}{llll}
\hline & \multicolumn{3}{l}{ Dependent variable (Organizational citizenship behavior) } \\
\cline { 2 - 4 } & $B$ & SE & t \\
\hline Constant & 5.46 & 0.09 & 62.02 \\
LMX & 0.59 & 0.12 & 5.04 \\
POS & 0.21 & 0.08 & 2.72 \\
Interaction & -0.13 & 0.05 & -2.74 \\
R2 & 0.68 & & \\
\hline
\end{tabular}

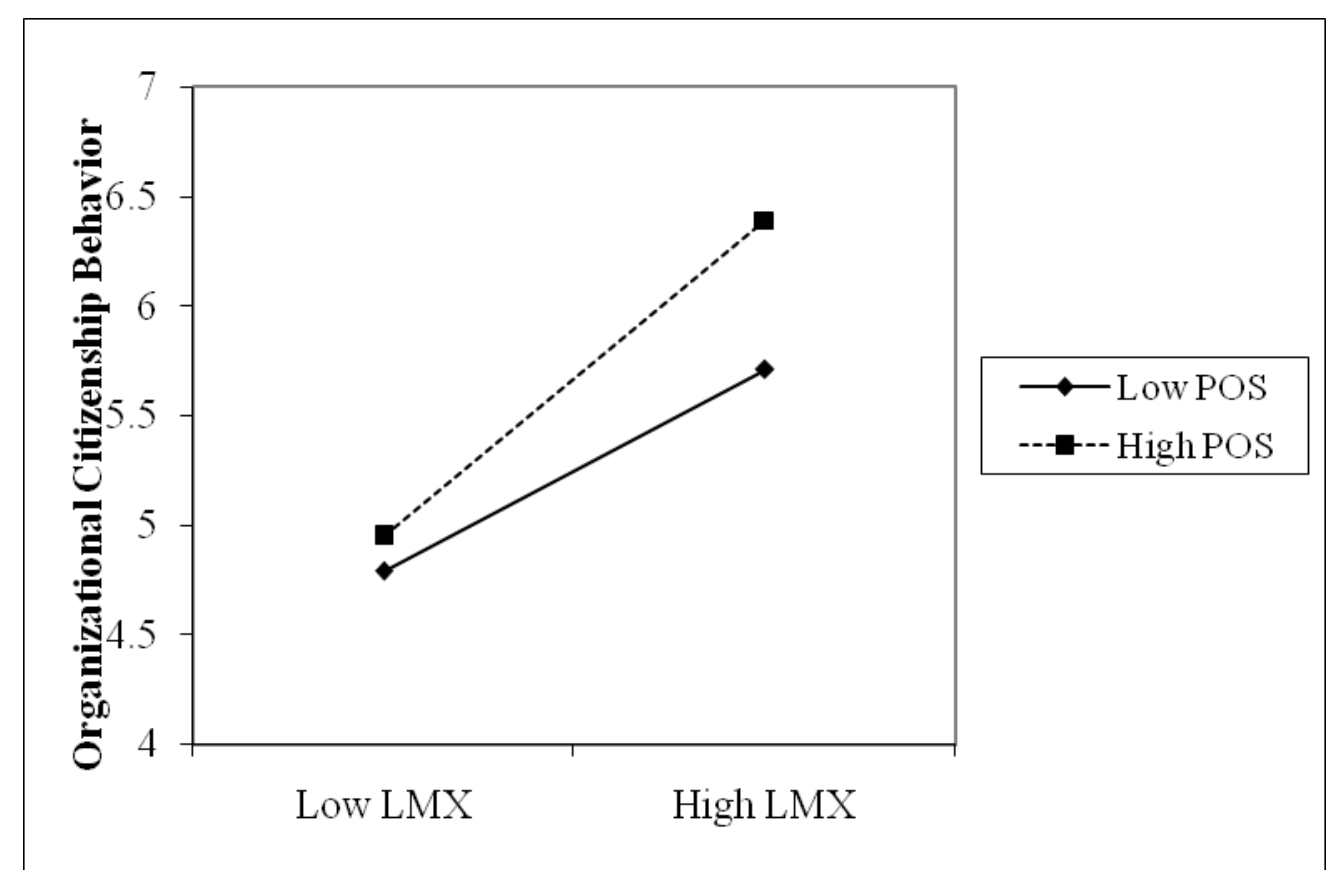

Figure 3. Subordinate POS as a moderator of LMX and OCB

\section{Discussion}

The link between LMX and POS is well established throughout OB literature; however, most of that research has committed a lot of time in establishing the distinction between these two constructs. Consequently, less attention has been devoted to examining how these constructs are related. Erdogan \& Ender's (2007) is one of the few the studies that has explored and established a relationship; however, the authors' study examined the research from a supervisory perspective. Although the incumbent study is not an indictment on Erdogan and Ender's (2007) study, it contends that focusing on the supervisor disregards the subordinate, who often is key to the social exchange processes that transpire within the organization. Therefore, the main focus of this study was to examine the degree to which subordinate POS moderated the relationship between LMX and various work outcomes. More specifically, this study predicted that subordinates with high POS would be more inclined to share those 
resources with their supervisors as a means to initiate or maintain high quality exchanges with their supervisors, which in turn would augment their satisfaction, commitment, and OCB.

The results of this study confirm predictions by illustrating how subordinate POS moderates the relationship between LMX and work outcomes (i.e. job satisfaction, organizational commitment, and OCB). Support for hypotheses can be largely explained in part due to the fact that when subordinates have high POS, they may have access to resources that subordinates with low POS do not possess. Therefore, these high POS subordinates become more attractive to supervisors who may not have access to those resources. These supervisors who lack the vital resources may actively engage in trying to recruit the high POS subordinates in an effort to gain access to the valuable resources. Due to the added attention and leverage that high POS subordinates possess, they are more like to experience higher levels of job satisfaction due to the access of valuable organizational resources and the added benefits of high LMX exchanges.

Likewise, the added attention and possession of valuable organizational resources can also lead to organizational commitment. Subordinates with high POS enjoy the benefits of having access to valuable organizational resources, which in turn will most likely lead to high LMX relationships with their supervisors who seek access to the same resources. Due to the advantages of enjoying benefits from both global and local exchanges, these subordinates are more likely to be committed to the organization. This finding highlights and supports the norm of reciprocity (Gouldner, 1960) as the high POS subordinates pay the organization back by staying with organization. Since a subordinate's commitment can be directed at different entities, it is conceivable that a high POS \& LMX subordinate would experience greater commitment than low POS subordinates. In addition, high POS \& LMX subordinates are least likely to be willing to forfeit the benefits of global and local exchanges. Therefore, they are more likely to stay with the organization.

The same phenomenon exists when we consider the moderation of subordinate POS in the relationship between LMX and OCB. This hypothesis was supported in part due to the reciprocity and spillover effects. For example, it is possible that when subordinates with high POS enjoy the benefits of having access to valuable organizational resources and the benefits of high LMX relationship with their supervisor, they may reciprocate these benefits by engaging in citizenship behaviors (i.e. helping others, etc.). In essence, they are more likely to indirectly reciprocate to the organization and/or their supervisor by helping their colleagues. The spillover effects emanate from the fact that an individuals' commitment can be directed at various entities (e.g. supervisor, coworkers, etc.) within the organization (Becker, 1992). A subordinate's commitment to his/her coworker will likely manifest in the subordinate engaging in OCB behaviors (i.e. helping their coworkers).

Overall, the findings of this study add a couple of salient contributions to the current literature. First, this study highlights the key role that subordinates play in the development of LMX relationships. Additionally, this finding supports Dulebohn et al., (2012) assertion that subordinates are equally important in the development of LMX relationships. This study is more profound due to the fact that it explicitly provides context of how the subordinate can be 
viewed as equal and in some cases, how the subordinate might have leverage in the development of LMX relationships. For example, a subordinate with high POS is more likely to have access to valuable resources that their supervisor may lack. Therefore, in an effort to gain access to those resources, the supervisor might actively recruit the high POS subordinate by offering them high LMX relationships. Indeed, the findings clearly show that these high POS subordinates are more likely to experience more job satisfaction and commitment while actively engaging in OCB.

The second contribution adds to the growing number of studies that highlights centrality of reciprocity in social exchange relationships. This study not only highlighted the importance of reciprocity in social exchange relationships, but also demonstrated the spillover effects of reciprocity. As previously noted, in an effort reciprocate their access to valuable organizational resources and high LMX relationships, subordinates do not discriminate on which entity their reciprocation is directed towards. For example, they could direct their reciprocation efforts towards the organization, supervisor, or coworkers. Therefore, even if high POS subordinates obtain their resources from the organization, they may reciprocate by paying it forward and sharing those resources with other organizational entities. This finding supports Erdogan and Enders' (2012) study that noted that exchanges between the organization-supervisor and supervisor-subordinates were intertwined.

\subsection{Implications}

The findings of this study provide some practical implications. Previous LMX studies have focused more on the supervisor in the LMX relationship development, however, the findings of this study clearly highlights the saliency of the subordinate in the LMX development process. This is particularly true if that subordinate has high POS, which seems to suggest a couple points. First, despite the lack of research showing the organization's influence in the LMX development, this study clearly shows that the organization can indeed influence this development by providing valuable resources to the parties involved. Ultimately, this seems to suggest that the organization can directly affect the work outcomes of subordinates in an effort to ensure that organizational goals are met. For example, the organization can circumvent a supervisor who is unwilling to engage his/her subordinates in high LMX by providing those disregarded subordinates with valuable resources which the supervisor may otherwise desire. This might force that supervisor to recruit and engage those subordinates into high LMX relationships, which in turn would positively affect their work outcomes and ultimately the organization's goals.

Second, despite previous assumptions that the organization would provide valuable resources to supervisors while neglecting the subordinates, the findings of this study clearly illustrate that organizations are just as likely to provide the valuable resources to the subordinate and/or supervisor. This finding is profound because it clearly shows that global and dyadic exchanges (Settoon et al., 1996) are not only interconnected, but transpire simultaneously. Therefore, both supervisors and subordinates alike might need training on how to stimulate high LMX relationships (Dulebohn et al., 2012). For example, a subordinate with high POS but low LMX 
might benefit from training that will help him/her to leverage the high POS into a high LMX relationship.

\subsection{Limitations and Future Research Directions}

Despite the positive findings of this study, it contains some inherent limitations. First, the study utilized self-reported data; therefore, common method bias may have been a factor. This bias can be reduced in future studies by utilizing triangulation (i.e. obtaining data from multiple sources). For example, data could have been collected from the supervisors and coworkers of the subordinates in an effort to curtail common method bias. Despite this limitation, some of the data collected could only be provided by the subordinates; therefore, triangulation would not have been possible. In addition, LMX was measured from a subordinate's perspective intentionally because subordinates with high POS might have leverage in influencing the LMX development process, so getting their perspective was imperative.

The second limitation is generalizability. The data was collected from a single engineering firm, which limits the generalizability of the results. Despite the collection of data from a single engineering firm, there is some level of confidence that the results are generalizable to other firms and industries that employ skilled and educated employees. Future research needs to utilize a more representative sample of participants from various industries with varying skills and education.

A third limitation of this study is the fact that the valuable resources that high POS subordinates might be afforded by the organization were not measured. This was a major assumption of the study that these resources exchanged between the organization and subordinate were valuable to both the subordinates and supervisors. Furthermore, these resources were required by both parties in order to accomplish their task, goals, etc. It is likely that subordinates with high POS did not have access to these resources but felt that the organization cared about their well-being. This could potentially affect LMX development differently since supervisors might not actively recruit subordinates access to valuable resources. Therefore, future research should make a concerted to identify and measure the resources/benefits high POS subordinates are afforded by the organization.

Future research needs to explore whether there are distinctions in LMX development between supervisor POS and subordinate POS. One would expect some differences to occur to varying degrees, but an empirical study would definitively establish whether such a distinction may or may not occur. For example, this study has shown that when subordinates have high POS, their supervisors will actively try to engage them and establish high LMX relationships. Previous studies have shown that when supervisors have high POS, their subordinates will actively seek to establish high LMX relationships with those supervisors (e.g. Erdogan \&Enders, 2007). Future research should also explore this phenomenon when both the supervisor and subordinate have high POS.

\section{Conclusion}

In conclusion, this study sought to examine the moderating effects of subordinate POS in the relationship between LMX and work outcomes. In other words, it examined how a 
subordinate's exchange with the organization affected their exchange relationship with their supervisor (LMX) and their work outcomes. The findings clearly show how subordinates with high POS strengthened the relationship between LMX and their work outcomes (i.e. job satisfaction, organizational commitment, and OCB). Future research should explore if these findings still hold in situations where both the supervisor and subordinate both have high POS (i.e. Will high supervisor and subordinate POS moderate the relationship between LMX and subordinate work outcomes?)

\section{References}

Allen, N. J., \& Meyer, J. P. (1990). The measurement and antecedents of affective, continuance and normative commitment to the organization. Journal of Occupational Psychology, 63, 1-18.https://doi.org/10.1111/j.2044-8325.1990.tb00506.x

Bauer, T. N., \& Green, S. G. (1996). Development of leader-member exchange: A longitudinal test. Academy of Management Journal, 39(6), 1538-1567. https://doi.org/10.2307/257068

Becker, T. E. (1992). Foci and bases of commitment: Are they distinctions worth making? Academy of Management Journal, 35(1), 232-244.https://doi.org/10.2307/256481

Blau, P. M. (1964). Exchange and power in social life. New York, NY: J Wiley \& Sons, Inc.

Brayfield, A. H., \& Rothe, H. R. (1951). An index of job satisfaction. Journal of Applied Psychology, 35, 307-311.https://doi.org/10.1037/h0055617

Dulebohn, J. H., Bommer, W. H., Liden, R. C., Brouer, R. L., \& Ferris, G. R. (2012). A meta-analysis of antecedents and consequences of leader-member exchange integrating the past with an eye toward the future. Journal of Management, 38(6), 1715-1759. https://doi.org/10.1177/0149206311415280

Eisenberg, R., Huntington, R., Hutchison, S., \& Sowa, D. (1986). Perceived organizational

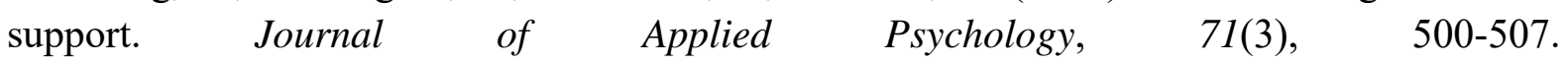
https://doi.org/10.1037/0021-9010.71.3.500

Eisenberger, R., Shoss, M. K., Karagonlar, G., Gonzalez-Morales, M. G., Wickham, R. E., \& Erdogan, B., \& Enders, J. (2007). Support from the top: supervisors' perceived organizational support as a moderator of leader-member exchange to satisfaction and performance $\begin{array}{lllll}\text { relationships. Journal of Applied } & \text { Psychology, }\end{array}$ https://doi.org/10.1037/0021-9010.92.2.321

Buffardi, L. C. (2014). The supervisor POS-LMX-subordinate POS chain: Moderation by reciprocation wariness and supervisor's organizational embodiment. Journal of Organizational Behavior, 35(5), 635-656. https://doi.org/10.1002/job.1877

Erdogan, B., Liden, R. C., \& Kraimer, M. L. (2006). Justice and leader-member exchange: The moderating role of organizational culture. Academy of Management Journal, 49(2), 395-406. https://doi.org/10.5465/AMJ.2006.20786086 
Fiske, S. T. (1993). Social cognition and social perception. Annual Review of Psychology, 44(1), 155-194. https://doi.org/10.1146/annurev.ps.44.020193.001103

Gouldner, A. W. (1960). The norm of reciprocity: A preliminary statement. American Sociological Review, 25, 161-177. https://doi.org/10.2307/2092623

Graen, G. B., \& Scandura, T. A. (1987). Toward a psychology of dyadic organizing. Research in Organizational Behavior, 9, 175-208.

Graen, G., \& Schiemann, W. (1978). Leader-member agreement: A vertical dyad linkage $\begin{array}{llll}\text { approach. Journal of Applied } & \text { Psychology, }\end{array}$ https://doi.org/10.1037/0021-9010.63.2.206

Graen, G. B., \& Uhl-Bien, M. (1995). Relationship-based approach to leadership: Development of leader-member exchange (LMX) theory of leadership over 25 years: Applying a multi-level multi-domain perspective. The Leadership Quarterly, 6(2), 219-247. https://doi.org/10.1016/1048-9843(95)90036-5

Hackman, J. R., \& Oldham, G. R. (1975). Development of the job design diagnostic survey. Journal of Applied Psychology, 60, 159-170. https://doi.org/10.1037/h0076546

Hayes, A. F. (2013). Introduction to mediation, moderation, and conditional process analysis: A regression-based approach. Guilford Press.

Illies, R., Wilson, K. S., \& Wagner, D. T. (2009). The spillover of daily job satisfaction onto employees' family lives: The facilitating role of work-family integration. Academy of Management Journal, 52(1), 87-102. https://doi.org/10.5465/AMJ.2009.36461938

Liden, R. C., Wayne, S. J., \& Sparrowe, R. T. (2000). An examination of the mediating role of psychological empowerment on the relations between the job, interpersonal relationships, and work outcomes. Journal of Applied Psychology, 85(3), 407-416. https://doi.org/10.1037/0021-9010.85.3.407

Masterson, S. S., Lewis, K., Goldman, B. M., \& Taylor, M. S. (2000). Integrating justice and social exchange: The differing effect of fair procedures and treatment on work relationships. Academy of Management Journal, 43(4), 738-748. https://doi.org/10.2307/1556364

Meyer, J. P., \& Allen, N. J. (1991). A three-component conceptualization of organizational commitment. Human Resource Management Review, 1(1), 61-89. https://doi.org/10.1016/1053-4822(91)90011-Z

Moorman, R. H., Blakely, G. L., \& Niehoff, B. P. (1998). Does perceived organizational support mediate the relationship between procedural justice and organizational citizenship behavior? Academy of Management Journal, 41(3), 351-357. https://doi.org/10.2307/256913

Organ, D. W., \& Near, J. P. (1985). Cognitive vs. affect measures of job satisfaction. International Journal of Psychology, 241-254. https://doi.org/10.1080/00207598508247735 
Rhoades, L., \& Eisenberger, R. (2002). Perceived organizational support: a review of the $\begin{array}{llll}\text { literature. Journal of Applied } & \text { Psychology, }\end{array}$ https://doi.org/10.1037/0021-9010.87.4.698

Roch, S. G., \& Shanock, L. R. (2006). Organizational justice in an exchange framework: Clarifying organizational justice distinctions. Journal of Management, 32(2), 299-322. https://doi.org/10.1177/0149206305280115

Scandura, T. A., \& Graen, G. B. (1984). Moderating effects of initial leader-member exchange status on the effects of a leadership intervention. Journal of Applied Psychology, 69(3), 428-436. https://doi.org/10.1037/0021-9010.69.3.428

Schriesheim, C. A., Castro, S. L., \& Cogliser, C. C. (1999). Leader-member exchange (LMX) research: A comprehensive review of theory, measurement, and data-analytic practices. The Leadership Quarterly, 10(1), 63-113. https://doi.org/10.1016/S1048-9843(99)80009-5

Schriesheim, C. A., Neider, L. L., Scandura, T. A., \& Tepper, B. J. (1992). Development and preliminary validation of a new scale (LMX-6) to measure leader-member exchange in organizations. Educational and Psychological Measurement, 52(1), 135-147. https://doi.org/10.1177/001316449205200119

Settoon, R. P., Bennett, N., \& Liden, R. C. (1996). Social exchange in organizations: Perceived organizational support, leader-member exchange, and employee reciprocity. Journal of Applied Psychology, 81(3), 219. https://doi.org/10.1037/0021-9010.81.3.219

Sparrowe, R. T., \& Liden, R. C. (1997). Process and structure in leader-member exchange. Academy of Management Review, 22(2), 522-552. https://doi.org/10.5465/AMR.1997.9707154068

Stevens, J. M., Beyer, J. M., \& Trice, H. M. (1978). Assessing personal, role and organizational predictors of managerial commitment. Academy of Management Journal, 21, 380-396. https://doi.org/10.2307/255721

Williams, L. J., \& Anderson, S. E. (1991). Job satisfaction and organizational commitment as predictors of organizational citizenship and in-role behavior. Journal of Management, 17, 601-617. https://doi.org/10.1177/014920639101700305

Walumbwa, F. O., Mayer, D. M., Wang, P., Wang, H., Workman, K., \& Christensen, A. L. (2011). Linking ethical leadership to employee performance: The roles of leader-member exchange, self-efficacy, and organizational identification. Organizational Behavior and Human Decision Processes, 115(2), 204-213. https://doi.org/10.1016/j.obhdp.2010.11.002

Wang, H., Law, K. S., Hackett, R. D., Wang, D., \& Chen, Z. X. (2005). Leader-member exchange as a mediator of the relationship between transformational leadership and followers' performance and organizational citizenship behavior. Academy of Management Journal, 48(3), 420-432. https://doi.org/10.5465/AMJ.2005.17407908 
Wayne, S. J., Coyle-Shapiro, J. A. M., Eisenberger, R., Liden, R. C., Rousseau, D. M., \& Shore, L. M. (2009). Social influences. Commitment in organizations: Accumulated wisdom and new directions, 253-284.

Wayne, S. J., Shore, L. M., Bommer, W. H., \& Tetrick, L. E. (2002). The role of fair treatment and rewards in perceptions of organizational support and leader-member exchange. Journal of Applied Psychology, 87(3), 590. https://doi.org/10.1037/0021-9010.87.3.590

Wayne, S. J., Shore, L. M., \& Liden, R. C. (1997). Perceived organizational support and leader-member exchange: A social exchange perspective. Academy of Management Journal, 40(1), 82-111. https://doi.org/10.2307/257021

Yang, J., Mossholder, K. W., \& Peng, T. K. (2009). Supervisory procedural justice effects: The mediating roles of cognitive and affective trust. Leadership Quarterly, 20(2), 143-154. https://doi.org/10.1016/j.leaqua.2009.01.009 